Document downloaded from:

http://hdl.handle.net/10251/48060

This paper must be cited as:

Macario, A.; Verri, F.; Díaz Morales, UM.; Corma Canós, A.; Giordano, G. (2013). Pure silica nanoparticles for liposome/lipase system encapsulation: Application in biodiesel production. Catalysis Today. 204:148-155. doi:10.1016/j.cattod.2012.07.014.

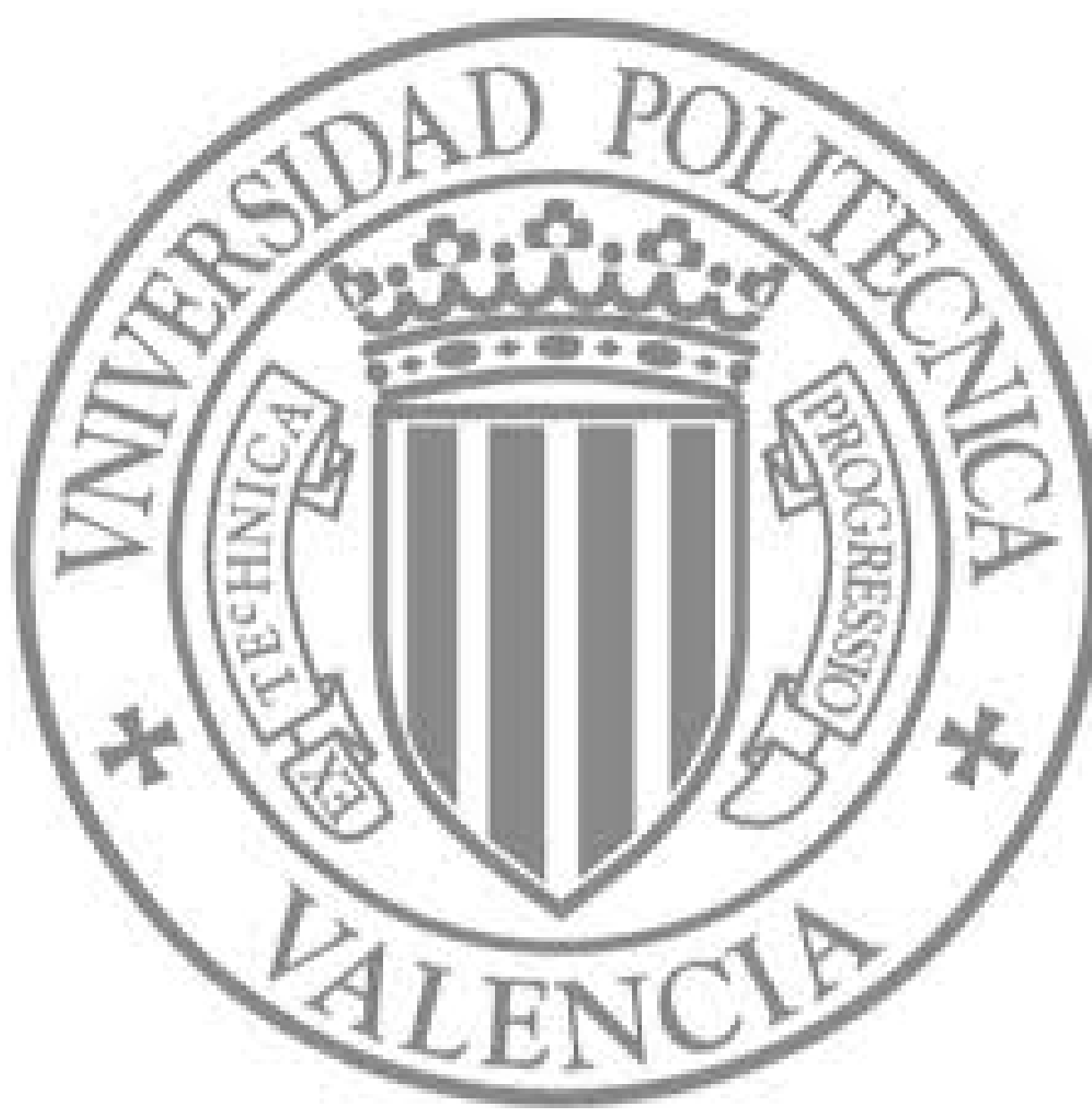

The final publication is available at

http://dx.doi.org/10.1016/j.cattod.2012.07.014

Copyright Elsevier 


\section{Elsevier Editorial System(tm) for Catalysis Today Manuscript Draft}

Manuscript Number: CATTOD-D-12-00316R1

Title: Pure silica nanoparticles for liposome/lipase system encapsulation: application in biodiesel production

Article Type: SI Article:Nanoporous\&Layered Materials

Keywords: Lipase, Liposome, Hybrid-nanospheres, Biodiesel, Heterogeneous Catalysis

Corresponding Author: Dr Anastasia Macario,

Corresponding Author's Institution:

First Author: Anastasia Macario, Senior Researcher

Order of Authors: Anastasia Macario, Senior Researcher; Francesca Verri; Urbano Diaz, Dr.; Avelino Corma, Prof.; Girolamo Giordano, Prof.

Abstract: In this work we report the synthesis of organic-inorganic solid with spherical morphology where enzyme, as active compounds, is encapsulated. The organic phase of nanospheres is composed of L- $\alpha$-phosphatidylcholine, as liposome, and Lipase from Rhizomucor miehei, as enzyme. The organic phase is covered with porous inorganic silica shell that could stabilize the internal liposomal phase and, consequently, isolate and protect the bioactive molecules. The liposome and silica amount used during the immobilization procedure have been optimized in order to obtain active and stable heterogeneous biocatalyst. Hybrid-nanospheres containing the enzyme were used to catalyze the transesterification reaction of triolein with methanol to methyl esters, typical biodiesel mixture compounds. The encapsulated enzyme retains its activity after 5 reaction cycles. The total productivity of the best catalyst obtained is higher than that of the free enzyme.

Suggested Reviewers: 
Contribution for the special issue of Catalysis Today related to Workshop Challenges in Nanoporous and Layered Materials for Catalysis

Dear Editor,

I am respectfully sending you our manuscript

Pure silica nanoparticles for liposome/lipase system encapsulation: application in biodiesel production

\author{
A. Macario, F. Verri, U. Diaz, A. Corma, G. Giordano
}

for publication in the Special Issue "Nanoporous and Layered Materials for Catalysis" of Catalysis Today Journal.

With kindest regards

Anastasia Macario 


\section{Answer to Comments}

Reviewer \#1: The authors in the article described a new method of preparation of encapsulated active biomolecules. The lipase enzymes in silica nanoparticles are catalytical more active for the transesterification reaction than free enzymes, even after 5 reaction cycles. I recommend the article for publication in Catalysis Today.

A: We want to thank the reviewer for the revision.

Reviewer \#2: The paper deals with an interesting topic and merits to be published in Catalysis Today. However, the following comments should be taken into account prior to final acceptance of the manuscript:

A: We have appreciated very much all the suggestions made by the reviewer. They have entailed important improvements of the manuscript.

Main comments:

Q1: What is the productivity compared with classical homogeneous catalysts and some heterogeneous catalysts reported in literature? Please provide a comparison.

A1: In order to make this comparison, we have introduced another paragraph, "Comparison with some homogeneous and heterogeneous catalysts", where we have compared the best performance of some heterogeneous catalysts and the classical homogeneous catalysts (basic, $\mathrm{KOH}$, and acid, $\mathrm{H}_{2} \mathrm{SO}_{4}$ ). Unfortunately, we don't have the productivity values for all these catalysts and, in any case, the tested enzyme amount and the number of reaction cycles should be the same, in order to make a good comparison. Therefore we have compared the overall catalytic performance. To do this comparison, we have inserted some references (from 15 to 19).

Q2: What is the reason for the rapid drop in activity after the fifth cycle? Please explain it in the text.

A2: Most probably, the main reason of the rapid drop of the enzyme activity after the fifth cycle should be the denaturation of the same enzyme, together with the inevitable leaching. We have introduced this consideration in the text, section 3.3 Transesterification reaction results, lines 54-55. 
Q3: It is said: "The possibility to use cheaper feedstock requires alternative catalysts instead of the homogeneous basic ones $(\mathrm{NaOH}, \mathrm{KOH}$ and $\mathrm{NaOCH} 3$ largely used in the industrial production of biodiesel)." Why? Elaborate on this please.

A3: We have introduced a new sentence with more details in order to better explain the concept:

Introduction part (lines 7-13):

"The possibility to use cheaper feedstock (reach in free fatty acids and water containing) requires alternative catalysts instead of the homogeneous basic ones $\left(\mathrm{NaOH}, \mathrm{KOH}\right.$ and $\mathrm{NaOCH}_{3}$ largely used in the industrial production of biodiesel).

In fact, the homogeneous basic transesterification shows a very fast kinetic of reaction but, also, a collateral saponification reaction that reduces the biodiesel production efficiency (low biodiesel yield and high catalyst consume). To prevent this drawback, oil and alcohol must be dry and the oil should have a minimum amount of free fatty acids (less than $0.1 \% \mathrm{wt}$ )."

Minor comments:

- Triolein $(60 \%)$ - what is the remaining $40 \%$ ?

The $40 \%$ is water. We have inserted this specification in the Experimental part (2.1 Materials section, line 6)

- n-Hexane is added before glycerol separation - is the separation possible without n-hexane addition?

Generally, the centrifugation is enough to separate products and reactants from glycerol. But, in order to well extract all compounds, before their GC-analysis, it is better to introduce a solvent (generally n-hexane) during the centrifugation. We have introduced this explanation in the Experimental part (2.3 Catalytic test section, line 7).

- Typos: please check: myristate / miristate, whit / with, which / witch We have made all corrections. Fig13 - should be yield not yeld, Fig. 12 should be free lipase, not fee. We have made all corrections. 
Dear Editor,

We apologize but, during the first version, we have forgotten to introduce the acknowledgements. If there are no problems, we would like to insert now this sentence in the manuscript, after the Conclusion section:

\section{Acknowledgements}

The authors, A.C. and U.D., thank the Spanish MICINN (Consolider

Ingenio 2010-MULTICAT (CSD2009-00050) and MAT2011-29020C02-01) for their financial support. 
Academy of Sciences of the Czech Republic

\section{J. Heyrovský Institute of Physical Chemistry}

Dolejškova 3, 18223 Prague 8, Czech Republic

Jiří Čejka

Phone $\quad(+420) 266053795$

Fax (+420) 286582307

E-mail CEJKA@jh-inst.cas.cz

Dr. Anastasia Macario

$\mathrm{PhD}$ Senior Researcher

University of Calabria

via P. Bucci - 42A/45A

87036 Rende - CS - Italy

Prague, May 12, 2012

Dear Dr. Macario,

I would like to invite you to submit a research manuscript for a special issue of Catalysis Today devoted to the International Workshop - Challenges in Nanoporous and Layered Materials for Catalysis, which will be held at Jeju Island on Aug 2-4, 2012.

Many thanks and very best wishes,

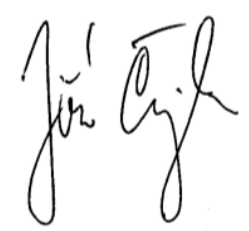

Prof. Jiri Cejka

Guest Editor 
Pure silica nanoparticles for liposome/lipase system encapsulation: application in biodiesel production

\author{
A. Macario, F. Verri, U. Diaz, A. Corma, G. Giordano
}

Highlights

- Active biomolecules for biodiesel production have been synthesized.

- Liposomes hybrid-nanospheresis a biocompatible microenvironment for lipase enzyme.

- External porous silica shell stabilizes the bioactive molecule.

- Productivity of best heterogeneous biocatalyst is higher than that of the free enzyme. 


\section{Pure silica nanoparticles for liposome/lipase system encapsulation: application in biodiesel production}

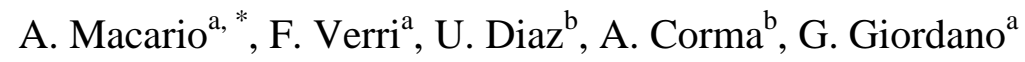

${ }^{\mathrm{a} D i p}$. Ing. Chim. \& Mat., Università della Calabria, via P. Bucci, 87036 (CS), Italy

' Instituto de Tecnología Química (UPV-CSIC), Universidad Politécnica de Valencia, Avda. de los Naranjos s/n 46022 Valencia, Spain

*corresponding author: email macario@ unical.it, telephone number +39.0984.49.66.67

Silica nanoparticles could be employed for storage of active biomolecules: their biocompatibility and stability towards external agents make them attractive systems to overcome the stability drawbacks of organic molecules. Enzyme-containing liposomes are interesting systems in which the biocatalyst is immobilized retaining its free and stable conformation, due to the biocompatible microenvironment inside the liposome membrane.

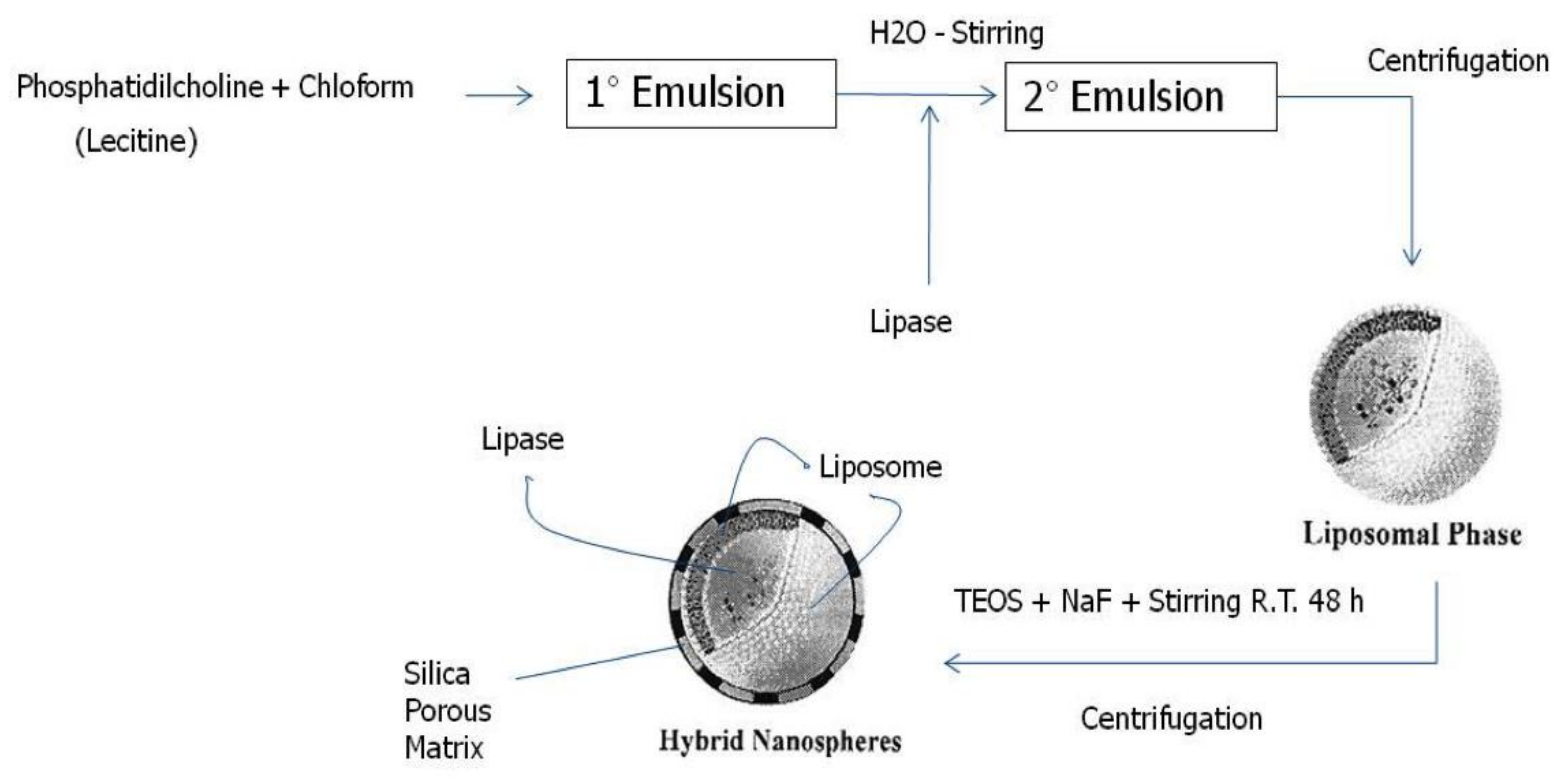

Figure 1. Preparation procedure of hybrid-nanospferes.

Hybrid-nanospheres containing the lipase enzyme were used to catalyze the transesterification reaction of triolein with methanol to methyl esters, typical biodiesel mixture compounds. The encapsulated enzyme retains its activity after 5 reaction cycles. The total productivity of the best catalyst obtained is higher than that of the free enzyme. 


\title{
Pure silica nanoparticles for liposome/lipase system encapsulation: application in biodiesel production
}

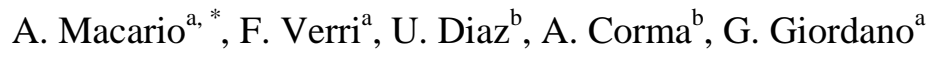 \\ ${ }^{a}$ Dip. Ing. Chim. \& Mat., Università della Calabria, via P. Bucci, 87036 (CS), Italy \\ ${ }^{\mathrm{b}}$ Instituto de Tecnología Química (UPV-CSIC), Universidad Politécnica de Valencia, Avda. de los Naranjos \\ s/n 46022 Valencia, Spain \\ *corresponding author: email macario@ unical.it, telephone number +39.0984.49.66.67
}

In this work we report the synthesis of organic-inorganic solid with spherical morphology where enzyme, as active compounds, is encapsulated. The organic phase of nanospheres is composed of L$\alpha$-phosphatidylcholine, as liposome, and Lipase from Rhizomucor miehei, as enzyme. The organic phase is covered with porous inorganic silica shell that could stabilize the internal liposomal phase and, consequently, isolate and protect the bioactive molecules. The liposome and silica amount used during the immobilization procedure have been optimized in order to obtain active and stable heterogeneous biocatalyst. Hybrid-nanospheres containing the enzyme were used to catalyze the transesterification reaction of triolein with methanol to methyl esters, typical biodiesel mixture compounds. The encapsulated enzyme retains its activity after 5 reaction cycles. The total productivity of the best catalyst obtained is higher than that of the free enzyme.

Keywords: Lipase, Liposome, hybrid-nanospheres, Biodiesel, Heterogeneous Catalysis

\section{Introduction}

Recently, scientific community has directed much attention toward innovative ways to produce biodiesel. The main drawback related to the production of this clean and renewable energy is the feedstock, $i$. e., the raw material (vegetable oils) useful for an efficient biodiesel conventional production process must be of high quality: low content of free fatty acids, water and unsaturated triglycerides. Oils with these properties are expensive and most appropriated for population food requirement.

The possibility to use cheaper feedstock (reach in free fatty acids and water containing) requires alternative catalysts instead of the homogeneous basic ones $(\mathrm{NaOH}, \mathrm{KOH}$ and $\mathrm{NaOCH}_{3}$ largely used in the industrial production of biodiesel). In fact, the homogeneous basic transesterification shows a very fast kinetic of reaction but, also, a collateral saponification reaction that reduces the biodiesel production efficiency (low biodiesel yield 
and high catalyst consume). To prevent these drawbacks, oil and alcohol must be dry and the oil should have a minimum amount of free fatty acids (less than $0.1 \%$ wt).

Into this approach, enzyme-catalyzed transesterification process is a promising and attractive alternative. Among the enzymes, lipases are the best ones for oils transesterification.

Lipases exhibit several advantages compared to the homogeneous base catalysts, such as high catalytic activity for the reaction carried out under moderate conditions, ability to process vegetable oils containing high degree of free fatty acid and water, reducing the formation of soaps and emulsions.

Recently, several studies have been carried out using Lipase as catalyst in the enzymatic transesterification of vegetable oils. Linko et al. have achieved the production of a variety of esters and biodegradable polyesters using lipase as a biocatalyst. They used the lipase derived from Candida Rugosa, in powder form, for transesterification of turnip seed oil in the presence of organic solvent (2-ethyl-1hexanol), obtaining esters conversion of the 97\% [1]. De et al., instead, studied the process of transesterification of the mango oil with different types of alcohol (C4-C18) using heterogeneous Mucor miehei lipase catalyst (Lipozyme IM-20), in absence of organic solvent, with conversions between 88.6 and 99.2\% [2]. Transesterification of triglycerides from sunflower oil, fish oil and waste oil from restaurants, in the presence of ethanol and using lipase from Candida Antarctica and Pseudomaonas cepacia, have been also studied [3]. Soumana et al. studied the catalytic behavior of different lipase immobilized on different supports such as: lipase from Candida antartica immobilized on polymer EP100, lipase from $P$. fluorescens immobilized on celite, lipase from Rhizomucor miehei entrapped in inorganic resin (Lipozyme RM IM) [4]. Again, studies concerning the production of esters by transesterification of oils recycled from restaurants using lipase from $P$. cepacea as catalyst, free and entrapped in a sol-gel matrix, have been carried out [5]. Several solid materials, such as ceramics, kaolinites, silica, cellulose, polymers, zeolites and mesoporous matrixes have been used as support for enzymes immobilization [6-9]. Moreover, several methods for the enzyme immobilization are available: adsorption, covalent binding, crosslinking and containment behind a barrier (micro-encapsulation, entrapment and confinement). As demonstrated in all the above-mentioned scientific works, the main aspects to highlight, in the heterogeneous biocatalyst preparation, are the activity and the stability preservation of the immobilized enzyme.

Generally, the medium in which the enzyme is immobilized is much important in order to preserve its natural and active conformation. From this point of view, to entrap enzyme within a natural aqueous-containing membrane should be suitable. Liposomes are interesting medium in which 
enzymes can preserve their natural and active conformation, because they are lipid vesicles in which a microaqueous volume is enclosed by the lipid bilayer membrane [10].

On the best of our knowledge, there are some studies on lipase from Rhizomucor miehei (RML) immobilization on different kinds of support, but no data are currently available concerning the RML entrapped inside a liposome membrane.

From X-ray crystallographic studies, the molecular structure of RML has been elucidated [11]. The particular conformation of this enzyme suggests that its most suitable immobilization method has to involve the hydrophilic "lid" region of the globular protein, in order to activate its catalytic center. The opening of the lid exposes the hydrophobic catalytic center towards substrate, that can be decomposed. For their peculiar composition, liposomes are highly effective systems for the encapsulation of hydrophilic/lypophilic biomolecules by interaction with the aqueous or the phospholipidic phase which complement their structure [10].

In this work we report the synthesis of organic-inorganic nano-solid with spherical morphology where lipase (RML), as active compounds, is encapsulated. More specifically, these nanospheres are composed of a purely organic internal liposomal phase in which bioactive molecule (enzyme) is encapsulated in a microaqueous environment. The liposomal phase is covered with porous inorganic silica shell that could stabilize the internal liposomal phase and, consequently, isolate and protect the bioactive molecules. The liposome and silica amount used during the immobilization procedure have been optimized in order to obtain active and stable heterogeneous biocatalyst.

Hybrid-nanospheres containing the enzyme were used to catalyze the transesterification reaction of triolein with methanol to methyl esters, typical biodiesel mixture compounds. The catalytic test results of the immobilized enzyme have been compared with those obtained using the same amount of free enzyme. Productivity of both type of biocatalysts (free and immobilized) have been evaluated and compared, for a potential industrial application.

\section{Experimental}

\subsection{Materials}

Organic nanospheres (liposome+enzyme) were prepared using: L- $\alpha$-phosphatidylcholine (SigmaAldrich) as liposome, PALATASE 20000L (Novo) as lipase enzyme. This enzyme is a purified 1,3specific lipase (EC 3.1.1.3) from Rhizomucor miehei (RML). For the preparation of silica porous shell around the organic nanospheres was used tetraethyl orthosilicate (TEOS), as silica source, and sodium fluoride, as mineralizing agent. The reagents used for the transesterification reaction were 
triolein $(\mathbf{6 0 \%}$ in water), methanol $(99.9 \%)$ and n-hexane $(95 \%)$. All reagents used were commercially available from Sigma Chemical Co.

\subsection{Synthesis of hybrid nanospheres}

The synthesis of hybrid nanospheres was carried adapting a published procedure to the enzyme immobilization [12] and it consists in two operative and subsequently stages: preparation of liposome nanospheres encapsulating enzyme and formation of an inorganic porous silica shell around the organic nanospheres. A scheme of the preparation route is shown in Figure 1.

A specific amount of lecithin (see Table 1) was mixed with chloroform in order to dissolve it and to create a homogeneous solution. The solution was vigorously stirred for about 10 minutes, until to obtain an emulsion of yellow color. The solution was then placed in a rotavapor to remove the chloroform. Thereby, this solution was mixed with $40 \mathrm{~mL}$ of $0.2 \mathrm{M}$ phosphate buffer $\mathrm{pH}=7$ containing $7.1 \mathrm{~mL}$ of RML (commercial PALATASE). The suspension was maintained during 2 hours at $40^{\circ} \mathrm{C}$ with continuous stirring. Finally, in order to obtain homogeneous nanospheres, the liposomal/enzyme solution was extruded two times using cellulose filters with a pores diameter equal to 0.20 micron.

During the second stage, an external inorganic shell (silica porous matrix) was formed around the liposomes/enzyme nanospheres, previously synthesized: a specific amount of tetraethyl ortosilicate (see Table 1) was added to the $47 \mathrm{ml}$ of liposomal/enzyme solution. The suspension formed was stirred at $350 \mathrm{rpm}$, at room temperature, for 2 hours and following, $7.1 \mathrm{mg}$ of $\mathrm{NaF}$ was incorporated to initializing the condensation of silane groups. The stirring was maintained for 48 hours at room temperature. To separate the supernatant from the medium containing the enzyme (hybrid nanospheres), the mixture was centrifuged at $15000 \mathrm{rpm}$ for 30 minute. The recovered solid was washed with distilled water, dried at $30^{\circ} \mathrm{C}$ overnight and stored at $0^{\circ} \mathrm{C}$ to preserve the functionality of the enzyme until its catalytic use. The total protein concentration $(\mathrm{C},[\mathrm{mg} / \mathrm{mL}])$ of the initial solution and of the supernatant was calculated using UV absorption method at 280/205 nm [13], using the following equation:

$$
\mathrm{C}=\mathrm{ABS}_{205} /\left[27+120 *\left(\mathrm{ABS}_{280} / \mathrm{ABS}_{205}\right)\right]
$$

where $\mathrm{ABS}$ is the absorbance value at the 205 or $280 \mathrm{~nm}$. The quantity of protein adsorbed on the support was determined by a mass balance: $\mathrm{W}_{\text {Enz_imm }}=\left(\mathrm{C}_{\mathrm{o}} * \mathrm{~V}_{\mathrm{o}}\right)-\left(\mathrm{C}_{\mathrm{F}} * \mathrm{~V}_{\mathrm{F}}\right)$, where $\mathrm{C}_{0}$ is the initial protein concentration $(\mathrm{mg} / \mathrm{mL}) ; \mathrm{V}_{0}$ is the volume of the initial solution $(\mathrm{mL}) ; \mathrm{C}_{\mathrm{f}}$ and $\mathrm{V}_{\mathrm{f}}$ are the final protein concentration $(\mathrm{mg} / \mathrm{mL})$ and the final volume $(\mathrm{mL})$ of the supernatant, respectively. Liposome and silica amount were varied in order to observe their influence on the catalytic 
performance of heterogeneous biocatalyst prepared. Table 1 summarizes these specifications, for each prepared catalysts.

\subsection{Catalytic test}

The catalytic tests were carried out starting from the following reaction mixture: commercial triolein $(60 \%)$ as substrate, prepared heterogeneous biocatalysts (10wt\% with respect to triolein) and methanol (molar ratio oil:methanol equal 1:6). The reaction system was stirred at $350 \mathrm{rpm}$ and kept at $37{ }^{\circ} \mathrm{C}$ (optimal reaction temperature for RML activity), for all reaction time.

After the monitored reaction time, products and reagents were separated from the catalyst and the glycerin (formed as by-product) by centrifugation (10000 rpm for 10 minutes) after adding $10 \mathrm{ml}$ of hexane (95\% Sigma-Aldrich), in order to well extract all the methyl esters produced and reactants not converted. $1 \mu \mathrm{L}$ of hexane solution containing products of reaction (and unreacted reagents) was analyzed by gas chromatography using an Agilent 6890 gas chromatographer equipped with a Zebron ZB-5HT column $(\mathrm{L}=15 \mathrm{~m}$; ID $=0.32 \mathrm{~mm}$; film thickness $=0.10 \mathrm{~m})$. The temperature program of the oven was: $50^{\circ} \mathrm{C}$ for 1 minute, $15^{\circ} \mathrm{C} / \mathrm{min}$ until $180^{\circ} \mathrm{C}, 7$ minutes at $180^{\circ} \mathrm{C}, 30^{\circ} \mathrm{C} / \mathrm{min}$ until $380^{\circ} \mathrm{C}$ and 10 minutes to $380^{\circ} \mathrm{C}$.

In order to calculate the corrected area of each reactant and product present in the reaction mixture, the standards of following compound has been analyzed by GC and the correspondent response factor has been calculated: oleic acid; methyl oleate; myristic acid; methyl myristate; palmitic acid; methyl palmitate; mono-olein; di-olein; tri-olein. Tricaprin is used as internal standard.

The conversion of triglycerides and biodiesel yield were calculated by the following formula:

Triglyc.Conversion $\%=\left[\frac{\left(A_{M M}+A_{M O}+A_{M P}\right)+\left(A_{M A}+A_{P A}+A_{O A}\right)+A_{M G}+\left(A_{D G} * 2\right)}{\left(A_{M M}+A_{M O}+A_{M P}\right)+\left(A_{M A}+A_{P A}+A_{O A}\right)+A_{M G}+\left(A_{D G} * 2\right)+\left(3 * A_{T G}\right)}\right] * 100$

Biodiesel Yield $\%=\left[\frac{\left(A_{M M}+A_{M O}+A_{M P}\right)}{\left(A_{M M}+A_{M O}+A_{M P}\right)+\left(A_{M A}+A_{P A}+A_{O A}\right)+A_{M G}+\left(A_{D G} * 2\right)+\left(3 * A_{T G}\right)}\right] * 100$

where the A indicated the peak area of the component, corrected by corresponding response factor, while the subscript indicates the particular component: $\mathrm{A}_{\mathrm{MM}}=$ Correct Area of methyl myristate, $\mathrm{A}_{\mathrm{MO}}=$ Correct Area of methyl oleate, $\mathrm{A}_{\mathrm{MP}}=$ Correct Area of methyl palmitate, $\mathrm{A}_{\mathrm{MA}}=$ Correct Area of myristic acid, $\mathrm{A}_{\mathrm{PA}}=$ Correct Area of palmitic acid, $\mathrm{A}_{\mathrm{OA}}=$ Correct Area of oleic acid, $\mathrm{A}_{\mathrm{MG}}=$ 
Correct Area of monoglycerides, $\mathrm{A}_{\mathrm{DG}}=$ Correct Area of diglycerides and $\mathrm{A}_{\mathrm{TG}}=$ Correct Area of triglycerides.

After the reaction time, the catalyst recovered was washed two times with n-hexane and distillated water, and after dried at $30^{\circ} \mathrm{C}$ overnight, the biocatalyst was ready for next catalytic reaction cycle.

\section{Results and discussion}

\subsection{Lipase immobilization results}

In Table 1 the enzyme immobilization results are reported.

By the immobilization results it is possible to observe that, maintaining the ratio between liposome and silica equal to 1 (sample LL1 and LL4), the enzyme immobilization efficiency achieved is the highest $(93 \div 95 \%)$. When the liposome:silica ratio is lower (sample LL3) or higher (sample LL2) than the unit, the lowest immobilization efficiency $(89 \div 90 \%)$ is obtained. From the comparison between samples LL1 and LL2, samples with that same amount of silica but different amounts of lecithin (double quantity in the sample LL2 with respect to sample LL1), the increasing of lecithin doesn't cause an increasing of enzyme encapsulated amount. In the same way, increasing the amount of TEOS used but not the amount of lecithin, you have not any appreciable effect on the amount of immobilized enzyme (comparison between sample LL1 and LL3). Rather, increasing both the amount of lecithin and silica source, it is possible to increase the amount of encapsulated enzyme (sample LL4), obtaining the highest immobilization efficiency.

These results suggest that, in order to immobilize the highest amount of enzyme, the optimal weight ratio between liposome and silica should be 1 .

\subsection{Heterogeneous biocatalyst characterization results}

The incorporation of organic phase (liposome/lipase) into the external inorganic silica shell is also corroborated by thermogravimetric analysis results. At first, the thermogravimetric analysis was performed on the sample in which nanospheres does not contain enzyme, but only liposome with the outer shell of pure silica ("Blank sample"), in order to determine the peak that identifies the liposome presents in the hybrid nanospheres (Figure 2). The endothermic peak at $343^{\circ} \mathrm{C}$ indicates the presence of liposomal phase inside the hybrid nanospheres. The same analysis was carried out on free Lipase to obtain the peaks identifying the enzyme (the identify peaks are at $\mathrm{T} \approx 300^{\circ} \mathrm{C}$ and at $\mathrm{T} \approx 400^{\circ} \mathrm{C}$; DTA curve showed in Figure 3). 
When the lipase is encapsulated within the liposome surrounded by the inorganic shell of silica, the analysis results show all the peaks cited above, confirming the simultaneous presence of enzyme and liposome (Figure 3 - for representative sample LL2).

From the TGA curves of all samples, it is possible to identify three main sections of the weight loss: $25 \div 200^{\circ} \mathrm{C}, 200 \div 550^{\circ} \mathrm{C}$ and more than $550^{\circ} \mathrm{C}$ (Figure 4). In the first section, the weight loss is mainly due to the physical desorption of water. The second weight loss, generally accompanied by a considerable development of heat, can be attributed to the combustion or decomposition of organic species present in the sample (enzyme-liposome species). Above $550^{\circ} \mathrm{C}$, water due to the dehydroxylation of the silanol groups present in the silica matrix could be detected, but this phenomena has not been observed in all the analyzed samples.

In Table 2 the results of thermogravimetric analysis are summarized.

From the results showed in the Table 2, it is possible to observe as introducing more lecithin, even if no increasing in encapsulated enzyme amount is achieved, the weight loss of the organic phase increases, meaning that, probably, some nanospheres of liposome are without enzyme (sample LL2 versus sample LL1 and sample LL4 versus sample LL3). However, increasing the amount of silica introduced, with the same amount of lecithin (sample LL3 versus sample LL1), a weight loss decreasing of the organic phase is observed: this means that a larger amount of silica does not favor the complete encapsulation of enzyme and/or liposome. Finally, comparing samples LL4 and LL1, where both silica and liposome are double, the decreasing of organic phase encapsulation is observed, being again this effect associated to higher presence of silica amount into the synthesis gel (sample LL4).

The BET specific surface area measurement of each sample has also been made. Comparing the BET values between hybrid nanospheres containing liposome and enzyme with the nanospheres containing only the liposome (blank sample) it is possible to notice that both samples exhibit a standard plate type I isotherm corresponding to microporous materials (Figure 5). Moreover, it is possible to appreciate a marked slope variation at relative pressures $\left(\mathrm{p} / \mathrm{p}_{0}\right)$ close to 0.8 , being this fact owing to the existence of meso and macropores between the different organic-inorganic nanospheres. These results corroborate univocally that the external inorganic shell is essentially microporous and, although the general textural properties are not substantially modified by the introduction of enzymes into the synthesis gel, a light increase in the total surface area is appreciated in the samples which include lipase in the internal part.

The morphology of the hybrid-nanospheres was observed by HR-TEM technique. The Figure 6, TEM image related to the LL1 sample, clearly shows the presence of both shells: that of liposome 
and that of silica (see inset in Figure 6). Inside these nanospheres, water and lipase should be entrapped.

By these results it is possible to observe, also, that maintaining the ratio between silica and liposome equal to 1 , the nanospheres seem to be well covered by silica shell. This is the case of sample LL1 (Figure 6) and of the sample LL4 (Figure 7).

The nanospheres show similar dimension for both samples: $50 \div 200 \mathrm{~nm}$ for the sample LL1 and between $50 \div 250 \mathrm{~nm}$ for the sample LL4.

When the ratio silica:liposome is $1: 2$, the quantity of silica is not enough to cover all the nanospheres (sample LL2). In fact, only a very few isolated nanospheres are formed and several nanosphere not covered are visible (Figure 8).

When the amount of silica used is twice with respect liposome (silica: liposome $=2: 1$ ), the most homogeneous and regular morphology of nanospheres should be obtained, probably associated this effect to the thickness and density increase of external microporous shell. In fact, more dense nanospheres are appreciated from TEM micrographs (see Figure 9, sample LL3). This factor could be decisive to obtain more robust hybrid nanospheres with improved stability which would presumably be important from catalytic point of view.

\subsection{Transesterification reaction results}

Despite the results obtained in the immobilization process, it is necessary to evaluate whether the immobilized enzyme in the samples appears to be catalytically active or not. This type of enzyme, in its free and soluble form, has a closed shape in which the lid covers the catalytic center and, only in the presence of hydrophobic substrate, the lid moves away allowing the center opening and the conversion of the substrate [11]. When the enzyme is confined in or on a matrix, it is suitable that it is immobilized in its active form, which is supported by a bond between the lid and support. This must be done without deactivation of the catalytic center and, therefore, the interactions between the lid and support should preferably involve the amino acids of the lid instead of any other amino acid constituting the enzyme. In fact the amino acids present in the hinge region of the lipase lid have an important role, both in enzyme activation and in stabilization of the immobilized open enzyme form. Arginine (R86), a basic aminoacid, is the key amino acid in the hinge region of the lid [14]. Consequently, the involvement of R86 of the RML could play a very important role in the immobilization of this enzyme. Thus, the catalytic behavior of the immobilized enzyme could be significantly affected by the different types of binding forces involved.

To test the catalytic performance of all heterogeneous catalysts, the monitored reaction time was chosen after the catalytic test results carried out using the lipase in free form, in a range time 
between 0 and 24 hours. Based on these results, it was possible to observe that, after three hours of reaction, the plateau of both the curves (triolein conversion and biodiesel yield) was achieved (see Figure 10). Particularly, the conversion of triglycerides was equal to $96 \%$ and the biodiesel yield was equal to $86 \%$.

First of all, it is important to notice that catalytic tests using the blank samples have been carried out in order to understand if the silica matrix and the liposome give a catalytic conversion of the substrate. The results showed, for all blank sample tests, that no triolein conversion occurs.

The results reported in Figure 11 show the different catalytic performance of the prepared samples containing lipase enzyme, compared with the free lipase, for the first cycle of reaction.

After the second reaction cycle, the activities of the samples LL1 and LL4 strongly decrease (see Figure 12).

The different behavior of the catalysts may depend on the homogeneity and stability of the nanospheres produced by various silica/liposome ratio. The samples prepared by the silica/liposome ratio equal to 1 show the same behavior and, after the second reaction cycle, they loss the most part of their activity (samples LL1 and LL4). The sample LL2, prepared with the lowest ratio between silica and liposome (0.5), does not show appreciable activity most probably due to the lowest coverage of the lipase/liposome system due to the reduced amount of silica used during the synthesis.

The best sample seems to be the LL3 catalyst, prepared with the highest amount of silica (silica/liposome ratio equal to 2) and obtained with the highest homogeneity of the nanospheres.

This catalyst shows excellent catalytic performance, near to those of free lipase. This suggests that the enzyme has been immobilized in its activated form and the silica shell well protects the organic phase, because, with respect to the other samples, its activity is preserved also after the second reaction cycle, being this fact associated to the higher density of the external microporous silica shell which could avoid the decomposition of the enzyme after successive catalytic runs.

This last hypothesis is corroborated by the results obtained, for this sample, after several reaction cycles. The Figure 13 shows the catalytic performance of the LL3 sample after seven reaction cycles.

By these results it is possible to notice that the enzyme, encapsulated by the procedure reported for the sample LL3, well retains its activity after 5 reaction cycles. It should also be noted that there is a low enzyme leaching during the various tests. This is an important aspect that corroborates the hypothesis by which the catalytic efficiency is also due to the action performed by the silica shell that well covers the organic nanospheres (lipase/liposome system). The silica porous matrix increases the chemical stability of the liposome and consequently of the enzyme. In the case of the 
sample LL3, the most homogeneous and regular morphology of the prepared nanospheres has been obtained (using a double amount of the silica with respect of the other samples) and, for this reason, this sample has a more elevated chemical stability.

However, after five reaction cycles, the leaching of the enzyme inevitably occurs, together to the denaturation of the same enzyme. In any case, the total productivity of the enzyme immobilized is clearly superior to that of the equivalent amount of free enzyme (Figure 14).

These results clearly demonstrate that the most important aspect for an efficient enzyme immobilization procedure is the final conformation of the biocatalyst rather than the immobilized enzyme quantity.

\subsection{Comparison with some homogeneous and heterogeneous catalysts}

It should be interesting to compare the performance of the sample LL3 with the performance of main catalysts used for biodiesel production: the homogeneous basic and acid ones and other types of immobilized biocatalysts.

In Table 3 this comparison is summarized. It is possible to observe as the classical homogeneous basic catalyst $(\mathrm{KOH})$ is able to convert completely the substrate but the biodiesel yield is very low if compared with the value obtained by some enzymatic catalysts. This can be explained by the presence of undesired collateral saponification reaction, that strongly reduce the methyl ester production [15].

While, comparing the performance of classical homogeneous acid catalyst with the enzymatic catalysis results, it is possible to notice that a very high amount of alcohol is necessary in order to avoid the use of higher temperature [16]. This aspect strongly reduces the environmental benefit of bio-fuel production.

Finally, comparing the performance among the different type of heterogeneous biocatalysts, it is possible to observe as the lipase encapsulated into hybrid nanospheres permits to obtain, during the first reaction cycle, the highest substrate conversion and biodiesel yield. This suggests that, most probably, the final productivity achieved by this kind of enzyme should be the highest, too. To corroborate this assertion, specific tests should be performed starting from the same amount of different immobilized enzyme and for the same number of reaction cycles. Moreover, by this comparison, the lipase encapsulated, PAL 20 [6] and LL3, show the high stability with respect to the lipase adsorbed. Moreover the enzyme immobilized into the liposome nanospheres shows a faster triolein conversion with respect to the lipase encapsulated into mesoporous/surfactant matrix. This indicates that the biocatalyst is immobilized retaining its free and stable conformation, due to the biocompatible microenvironment inside the liposome membrane. 


\section{Conclusions}

Enzyme-containing liposomes are interesting systems in which the biocatalyst can be immobilized, retaining its free and stable conformation, due to the biocompatible microenvironment inside the liposome membrane.

The chemical stability of organic nanospheres could be improved by silica coverage.

Among our samples, the role of an optimal silica coverage of the nanosphers is clearly showed by the high stability of the sample LL3. The best liposome/lipase nanospheres silica coverage is achieved using a silica:liposome ratio equal to 2, during the heterogeneous biocatalysts preparation. After 5 reaction cycles, the total productivity of the best catalyst obtained is higher than that of the free enzyme.

\section{Acknowledgements}

The authors, A.C. and U.D., thank the Spanish MICINN (Consolider Ingenio 2010-MULTICAT (CSD2009-00050) and MAT2011-29020-C02-01) for their financial support. 


\section{References}

[1] Y.Y. Linko, M. Lamsa, X. Wu, J. Seppolo, P. Linko, J. Biotech., 66 (1998) 41-50.

[2] B. K. De, D. K. Bhattachuryya, D. K., C. Bandhu , J. Am. Oil. Chem. Soc, 76 (1999) 451-453.

[3] H. Fukuda, A. Kondo, H. Noda, J. Biosc. Bioeng., 92 (2001) 405-416.

[4] M.M. Soumanou, U.T. Bournsheuer, Enzym. Microb. Technol., 33 (2003) 97-103.

[5] A. F. Hsu, K. Jones, T. Foglia, W.N. Marner, Biotec. Appl. Biochem., 36 (2000) 181-186.

[6] A. Macario, M. Moliner, A. Corma, G. Giordano, Micropor. Mesopor. Mater., 118 (2009) 334340.

[7] F. Yagiz, D. Kazan, A.N. Akin., Chem. Eng. J., 134 (2007) 262-267.

[8] L. Costa, V. Brissos, F. Lemos, F.R. Ribeiro, J.M.S. Cabral. Bioprocess Biosyst. Eng., 32 (2009) 53-61.

[9] A.P.V. Gonçalves, J.M. Lopes, F. Lemos, F.R. Ribeiro , D.M.F. Prazeres, J.M.S. Cabral, M.R. Aires-Barros, J. Mol. Catal. B-Enzym., 1 (1996) 53-60.

[10] P. Walde, S. Ichikawa, Biomol. Eng. 18 (2001) 143-177.

[11] Z.S. Derewenda, U. Derewenda, G. Dodson, J. Mol .Biol., 227(1992) 818-839.

[12] A. Corma, U. Diaz, M. Arrica, E. Fernandez, I. Ortega, Angew. Chem. Int. Ed. 48 (2009) 6247-6250.

[13] S.P. Colowick and N. O. Kaplan:” Methods in ENZYMOLOGY', volume 91, Part I, pp.107, Ed. C.H.W. Hirs and S.N. Timasheff.

[14] S. Herrgard, C.J. Gibas, S. Subramaniam, Biochemistry, 39 (2000) 2921-2930. 
[15] A. Macario, G. Giordano, B. Onida, D. Cocina, A. Tagarelli, A.M. Giuffrè, App. Catal. A: Gen., 378 (2010) 160-168.

[16] S. Siler-Marinkovic, A. Tomasevic, Fuel, 77 (12) (1998) 1389-1391.

[17] A. Macario, G. Giordano, L. Setti, A. Parise, J.M. Campelo, J.M. Marinas, D. Luna, Biocatal. Biotrans., 25 (2-4) (2007) 328-335.

[18] A. Macario, G. Giordano, P. Frontera, F. Crea, L. Setti, Catal. Lett., 122 (2008) 43-52;

[19] M.M. Soumanou, U.T. Bornscheuer, Eur. J. Lipid Sci. Technol., 105 (2003) 656-660. 


\section{Tables}

Table 1. Characteristic of prepared samples and enzyme immobilization results. For the samples containing enzyme, the starting solution contained $7.1 \mathrm{~mL}$ of Palatase

\begin{tabular}{|c|c|c|c|c|c|}
\hline $\begin{array}{l}\text { Sample } \\
\text { code }\end{array}$ & $\begin{array}{c}\text { Lecithin } \\
\text { amount } \\
{[\mathrm{g}]}\end{array}$ & $\begin{array}{c}\text { Amount of silica source } \\
\text { (TEOS) } \\
{[\mathrm{g}]}\end{array}$ & $\begin{array}{c}\text { Immobilized } \\
\text { Enzyme } \\
{[\mathrm{mg}]}\end{array}$ & $\begin{array}{c}\text { Immobilization } \\
\text { Efficiency } \\
{[\%]}\end{array}$ & $\begin{array}{c}\text { mg Immob. } \\
\text { Enzyme/g SiO }\end{array}$ \\
\hline BL1 & 0.44 & 0.44 & - & - & - \\
\hline LL1 & 0.44 & 0.44 & 236 & 93 & 536 \\
\hline BL2 & 0.88 & 0.44 & - & - & - \\
\hline LL2 & 0.88 & 0.44 & 226 & 89 & 514 \\
\hline BL3 & 0.44 & 0.88 & - & - & - \\
\hline LL3 & 0.44 & 0.88 & 230 & 90 & 261 \\
\hline BL4 & 0.88 & 0.88 & - & - & - \\
\hline LL4 & 0.88 & 0.88 & 241 & 95 & 274 \\
\hline
\end{tabular}

$\mathrm{BL}=$ blank sample, without enzyme

LL = sample with Liposome and Lipase

All results are the means of three repeated experiments

Table 2. Thermogravimetric analysis results of the hybrid nanospheres

\begin{tabular}{|c|c|c|c|c|c|c|}
\hline \multirow[b]{2}{*}{ Sample Code } & \multirow{2}{*}{$\begin{array}{c}\text { Lecithin } \\
\text { quantity } \\
\quad[\mathrm{g}]\end{array}$} & \multirow{2}{*}{$\begin{array}{c}\text { Silica } \\
\text { amount } \\
{[\mathrm{g}]}\end{array}$} & \multirow{2}{*}{$\begin{array}{c}\text { mg of } \\
\text { Encapsulated } \\
\text { Enzyme } \\
{[\mathrm{mg}]}\end{array}$} & \multicolumn{3}{|c|}{ WEIGHT LOSS [\%] } \\
\hline & & & & $25 \div 200^{\circ} \mathrm{C}$ & $200 \div 550^{\circ} \mathrm{C}$ & $\begin{array}{c}25-950^{\circ} \mathrm{C} \\
\text { (Total Weight loss) }\end{array}$ \\
\hline LL1 & 0.44 & 0.44 & 236 & 8 & 63 & 72 \\
\hline LL2 & 0.88 & 0.44 & 226 & 8 & 69 & 77 \\
\hline LL3 & 0.44 & 0.88 & 230 & 10 & 48 & 59 \\
\hline LL4 & 0.88 & 0.88 & 241 & 15 & 51 & 67 \\
\hline
\end{tabular}


Table 3. Comparison among the best performance of different catalysts.

\begin{tabular}{|c|c|c|c|c|}
\hline $\begin{array}{l}\text { Catalyst } \\
\text { Name }\end{array}$ & Type of catalyst & $\begin{array}{c}\text { Substrate } \\
\text { Conversion } \\
{[\%]}\end{array}$ & $\begin{array}{c}\text { Biodiesel Yield } \\
{[\%]}\end{array}$ & $\begin{array}{c}\text { Reaction Conditions } \\
\text { (time, temp., solvent:oil) }\end{array}$ \\
\hline $\mathrm{KOH}_{[15]}$ & Basic Homogeneous & 99 & 80 & $\begin{array}{c}24 \mathrm{~h} \\
70^{\circ} \mathrm{C} \\
10: 1\end{array}$ \\
\hline $\mathrm{H}_{2} \mathrm{SO}_{4}[16]$ & Acid Homogeneous & Good* & 97 & $\begin{array}{c}4 \mathrm{~h} \\
65^{\circ} \mathrm{C} \\
200: 1\end{array}$ \\
\hline $\begin{array}{c}\text { Lipase/S1 } \\
\quad[17,18]\end{array}$ & Adsorbed Lipase on Silicalite-1 & 99 & 80 & $\begin{array}{c}3 \mathrm{~h} \\
37^{\circ} \mathrm{C} \\
5: 1\end{array}$ \\
\hline $\begin{array}{l}\text { Ripozyme }_{[19]} \\
\text { RM }\end{array}$ & $\begin{array}{c}\text { Immobilized Lipase } \\
\text { on anion exchange resin }\end{array}$ & 90 & n.a. & $\begin{array}{c}25 \mathrm{~h} \\
40^{\circ} \mathrm{C} \\
3: 1\end{array}$ \\
\hline PAL20 [6] & $\begin{array}{l}\text { Encapsulated Lipase in } \\
\text { mesoporous/surfactant matrix }\end{array}$ & 90 & 78 & $\begin{array}{c}50 \mathrm{~h} \\
37^{\circ} \mathrm{C} \\
6: 1\end{array}$ \\
\hline LL3 & $\begin{array}{l}\text { Encapsulated Lipase in hybrid } \\
\text { nanospheres }\end{array}$ & 98 & 89 & $\begin{array}{c}3 \mathrm{~h} \\
37^{\circ} \mathrm{C} \\
6: 1\end{array}$ \\
\hline
\end{tabular}

* No better specification are reported 


\section{Figure captions}

Figure 1. Preparation procedure of hybrid-nanospferes.

Figure 2. DTA and TGA curve for the blank solid BL1 (nanospheres containing only liposome and external shell of pure silica).

Figure 3. DTA curves of the LL2 sample (representative sample) and free lipase.

Figure 4. TGA and DTA curves of sample LL1 (representative sample).

Figure 5. Nitrogen adsorption isotherms of LL1 and BL1 samples.

Figure 6. TEM image of sample LL1 $(\varnothing=50-200 \mathrm{~nm})$.

Figure 7. TEM image of sample LL4 $(\varnothing=50-250 \mathrm{~nm})$.

Figure 8. TEM image of sample LL2 $(\varnothing=50-100 \mathrm{~nm})$.

Figure 9. TEM image of sample LL3 $(50-250 \mathrm{~nm})$.

Figure 10. Reaction time profile of free lipase.

Figure 11. Performance of catalysts in the transesterification reaction of triolein (first cycle). Reaction condition: $3 \mathrm{~h}$ at $37^{\circ} \mathrm{C}$, enzyme amount $164 \mathrm{mg}$ in all samples. Catalyst amount (containing lipase/liposome/silica) for each sample: $0.426 \mathrm{~g}$ for LL1; $0.484 \mathrm{~g}$ for LL2; $0.745 \mathrm{~g}$ for LL3; $0.763 \mathrm{~g}$ for LL4).

Figure 12. Performance of catalysts in the transesterification reaction (second cycle).

Figure 13. Catalytic result obtained from LL3 sample after 7 reaction cycles.

Figure 14. Productivity comparison after 5 reaction cycles: immobilized (sample LL3) and free enzyme. 
Figures

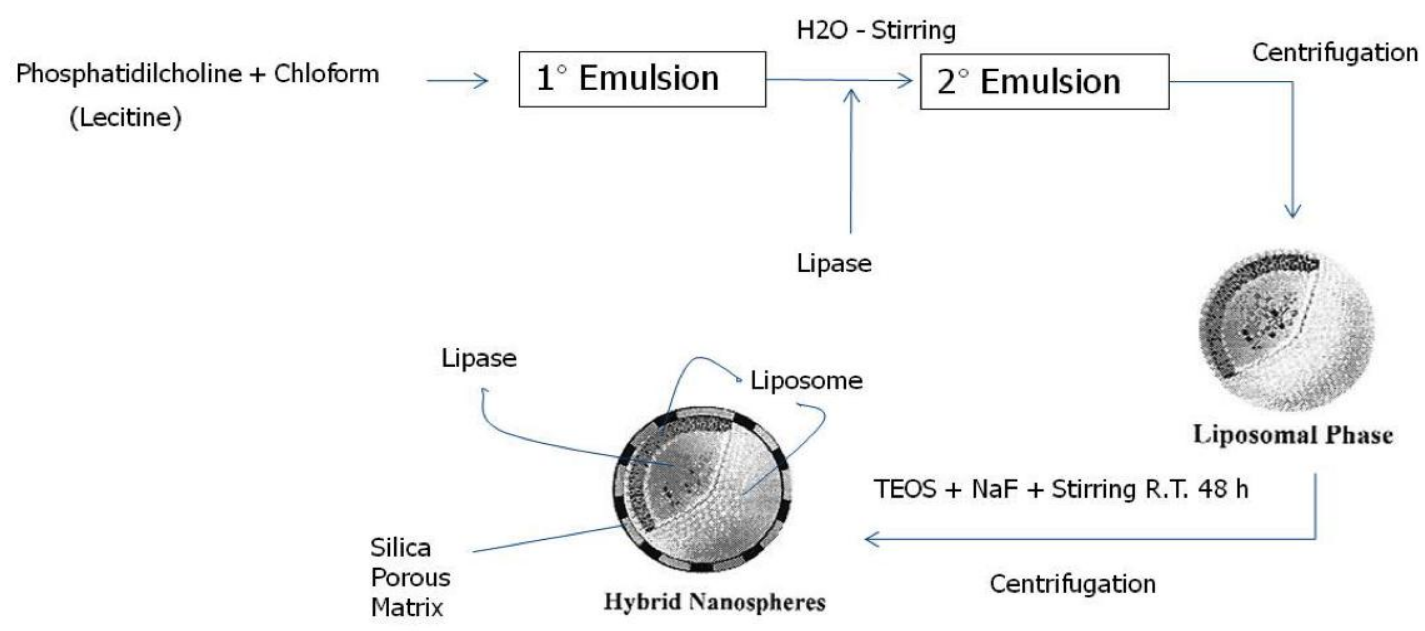

Figure 1

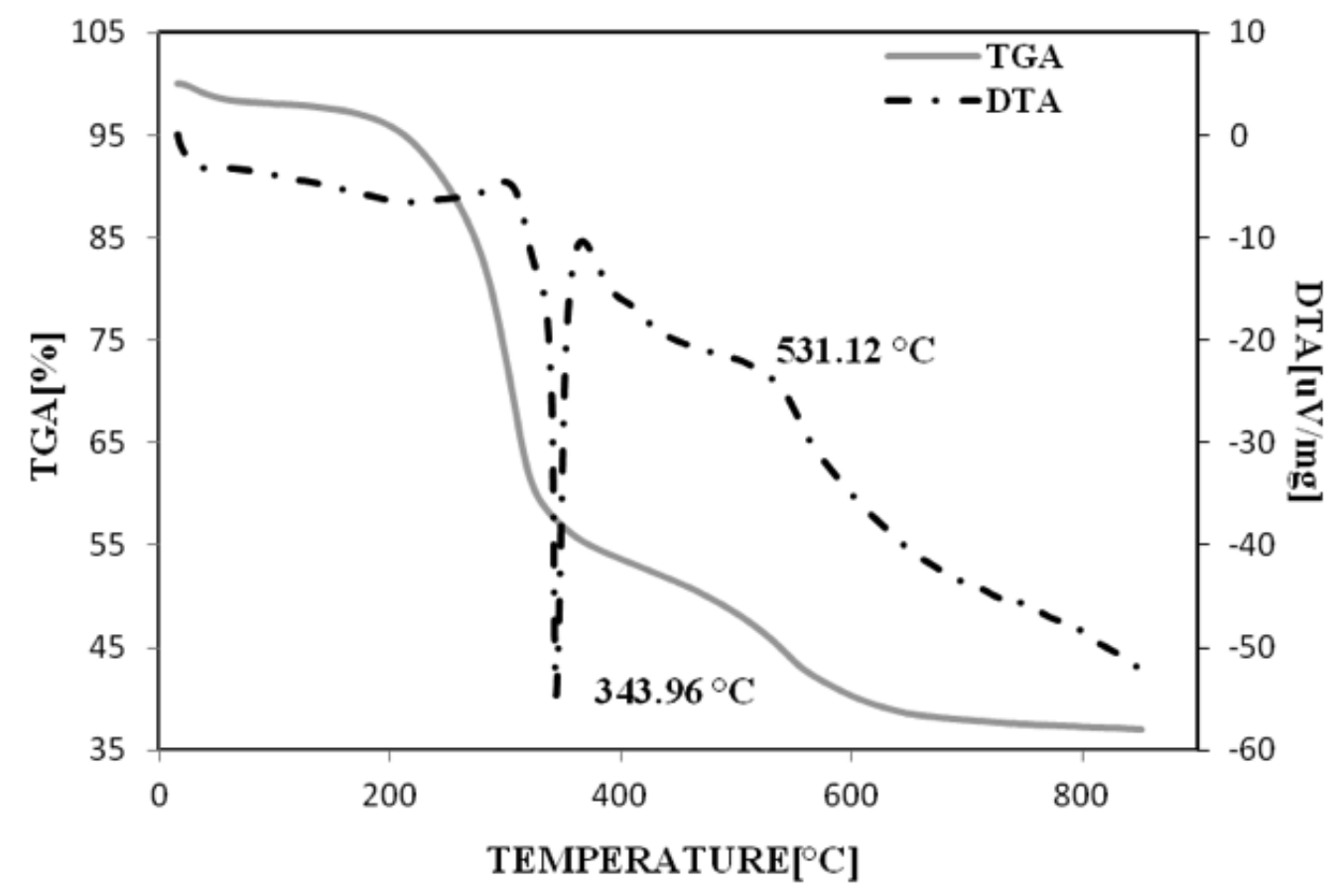

Figure 2 


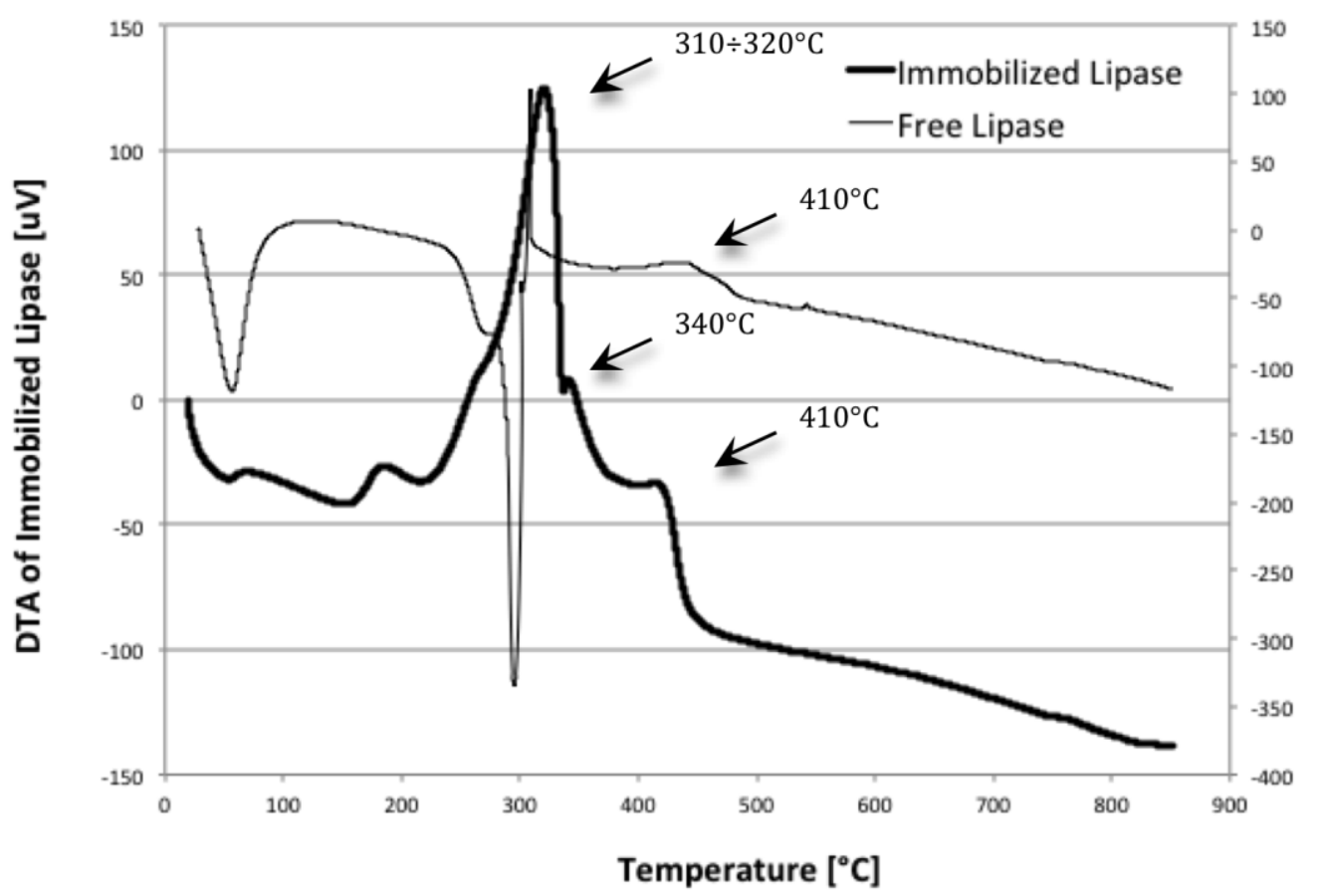

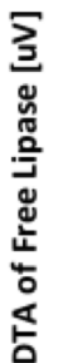

Figure 3

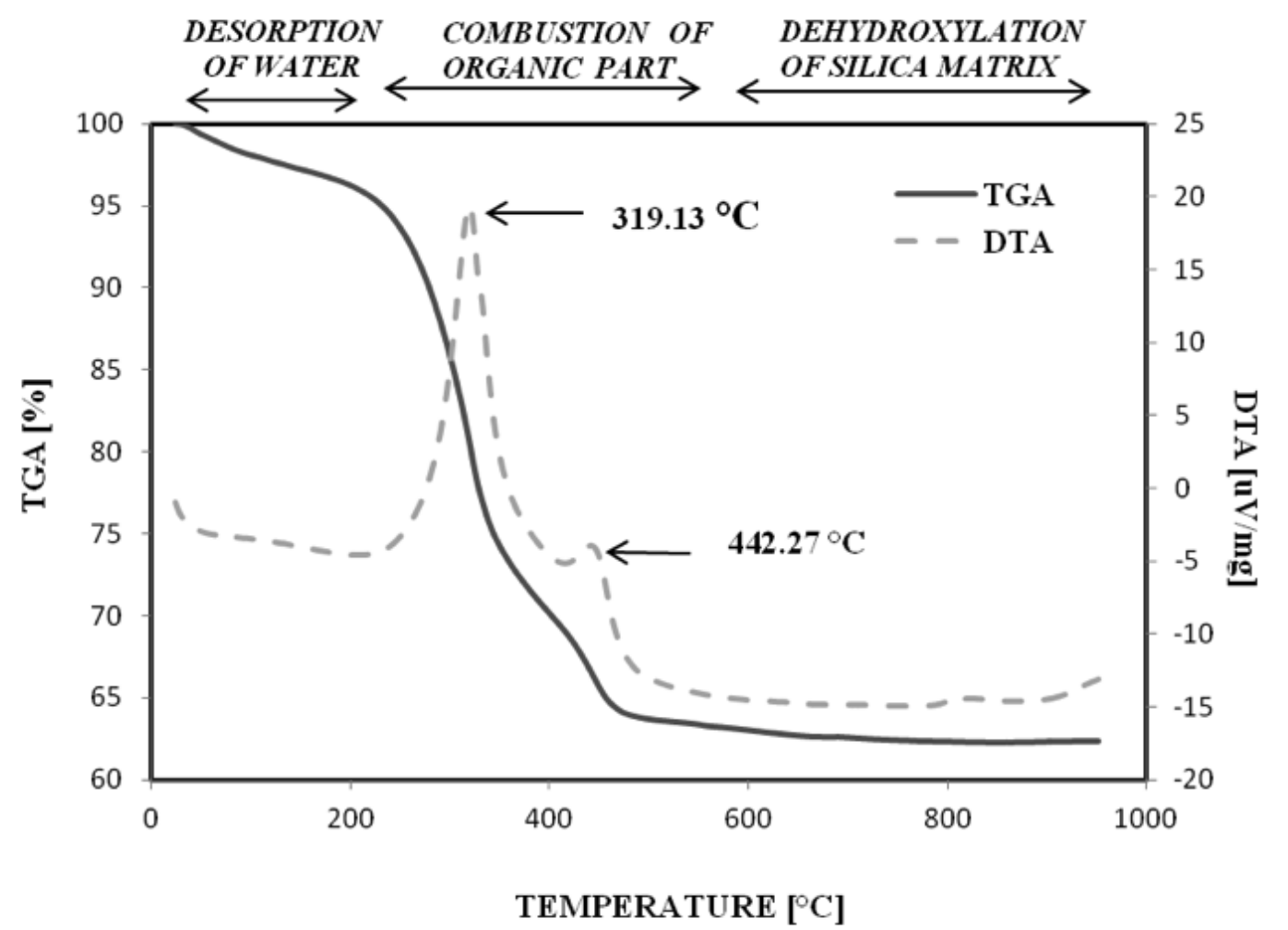

Figure 4 


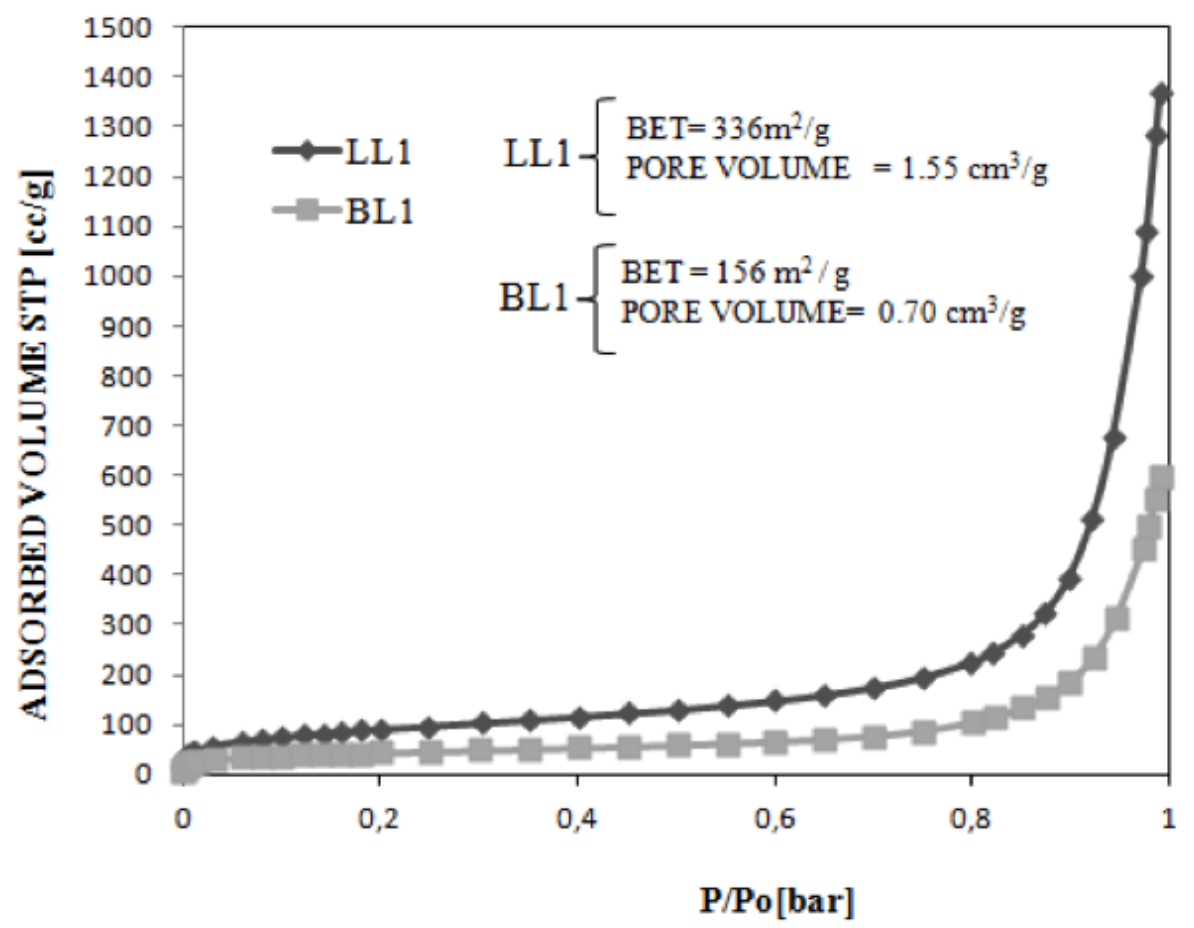

Figure 5

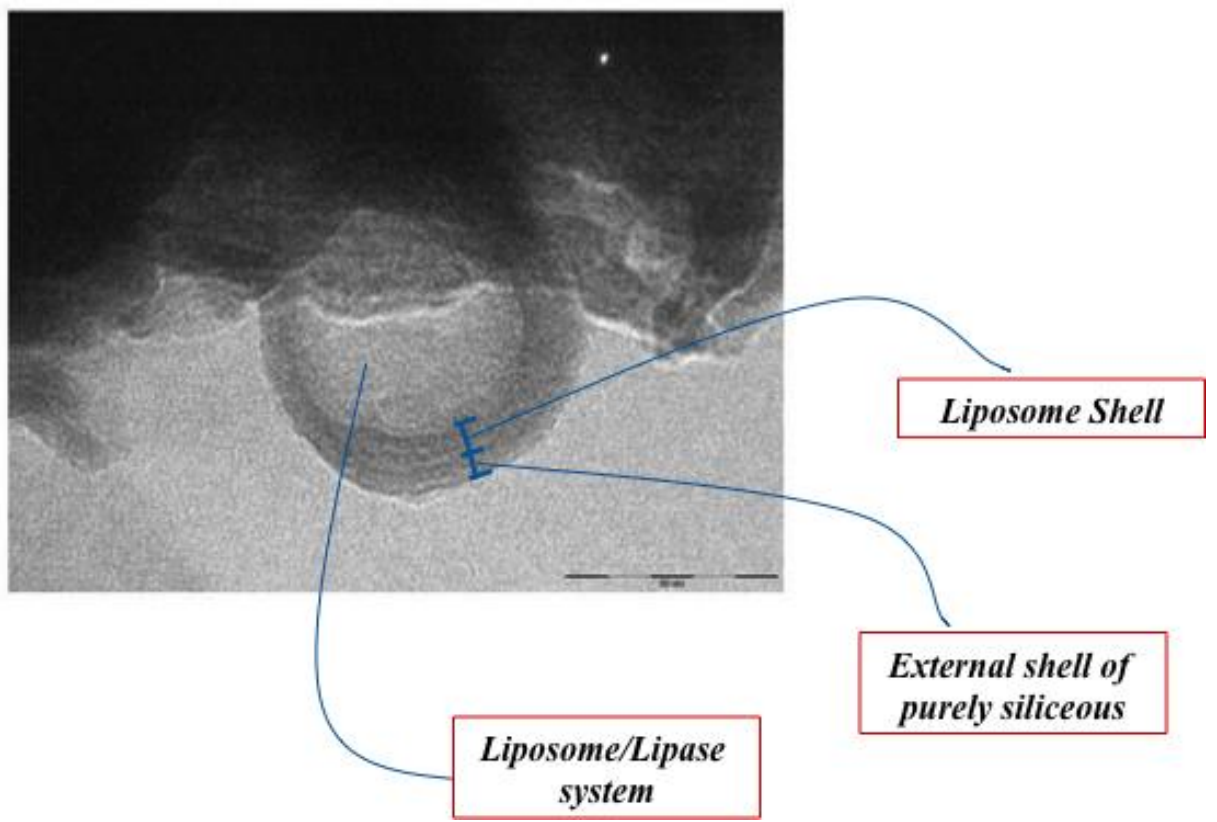

Figure 6 


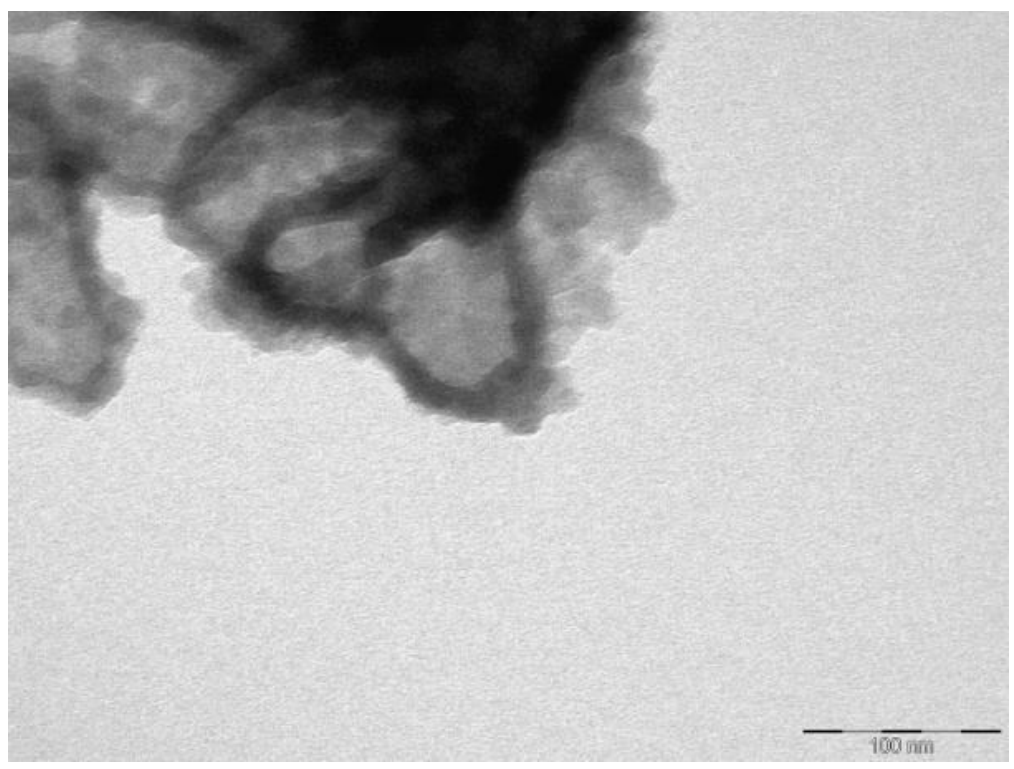

Figure 7

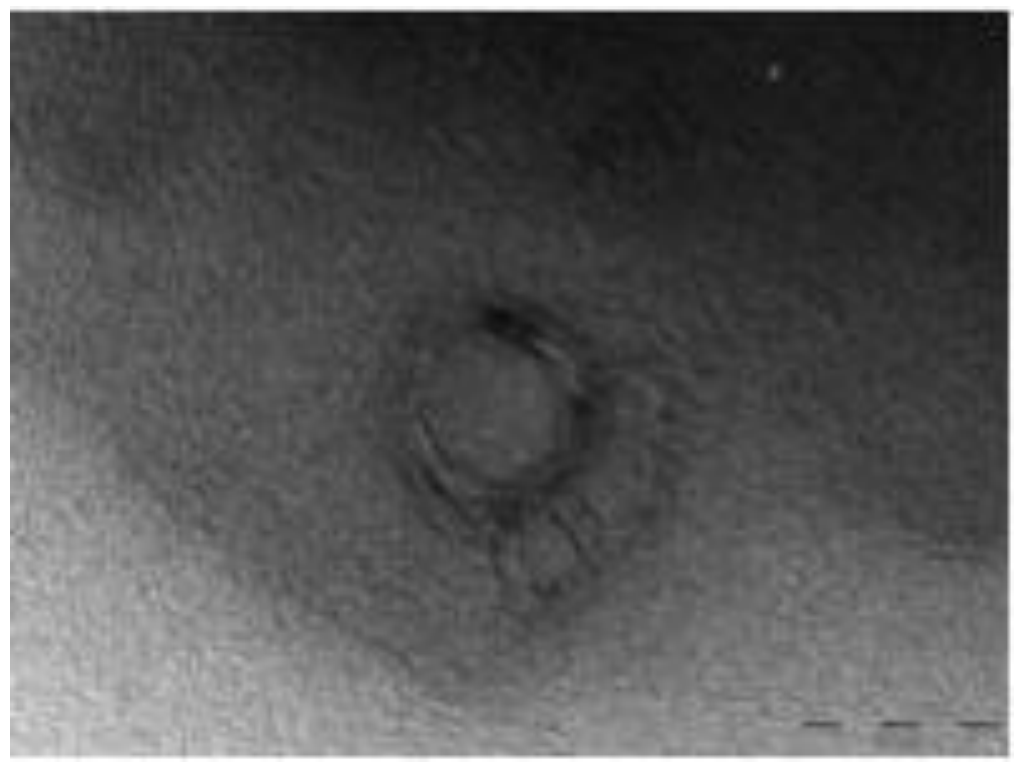

Figure 8 


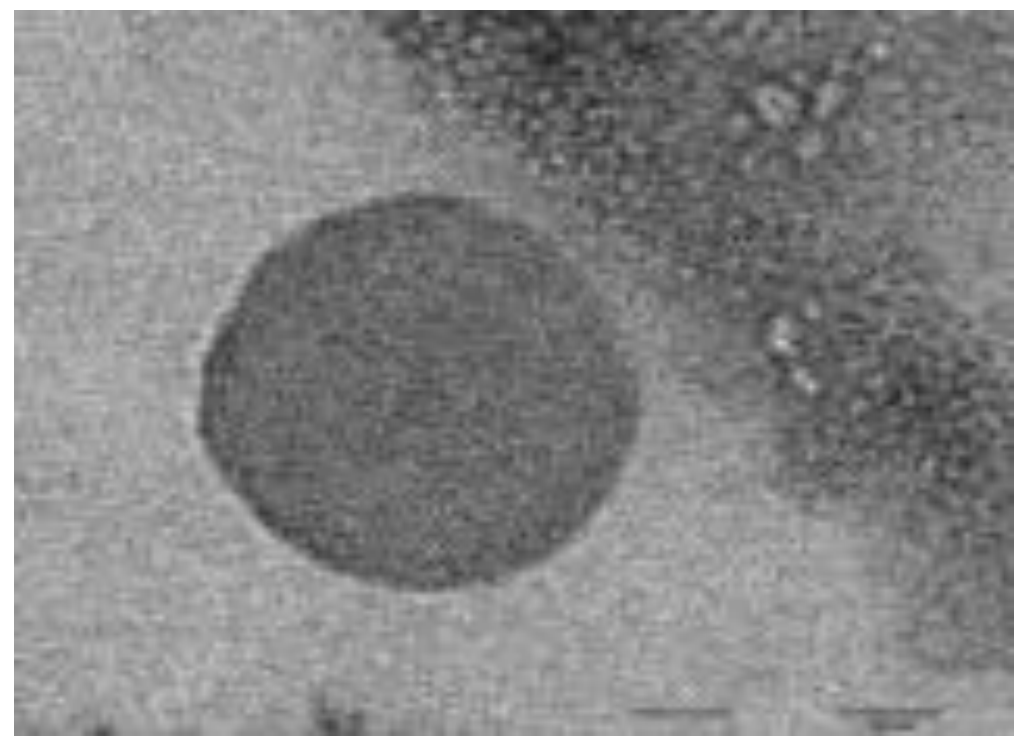

Figure 9

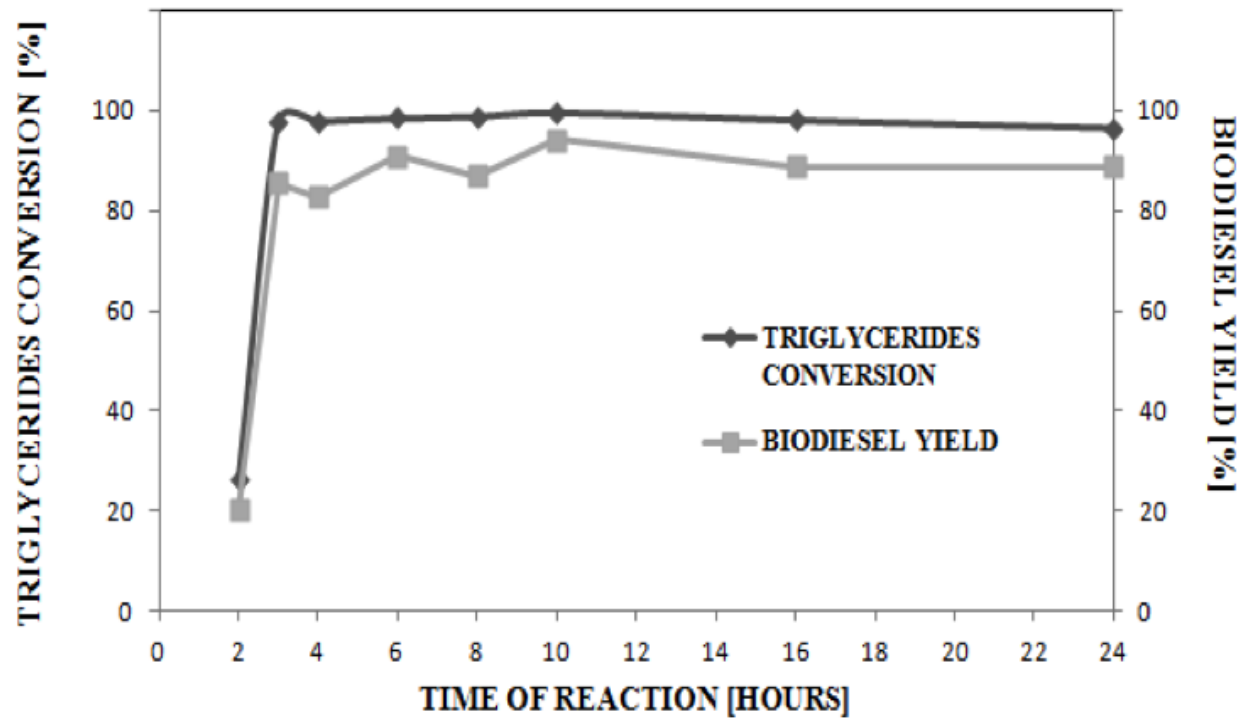

Figure 10 


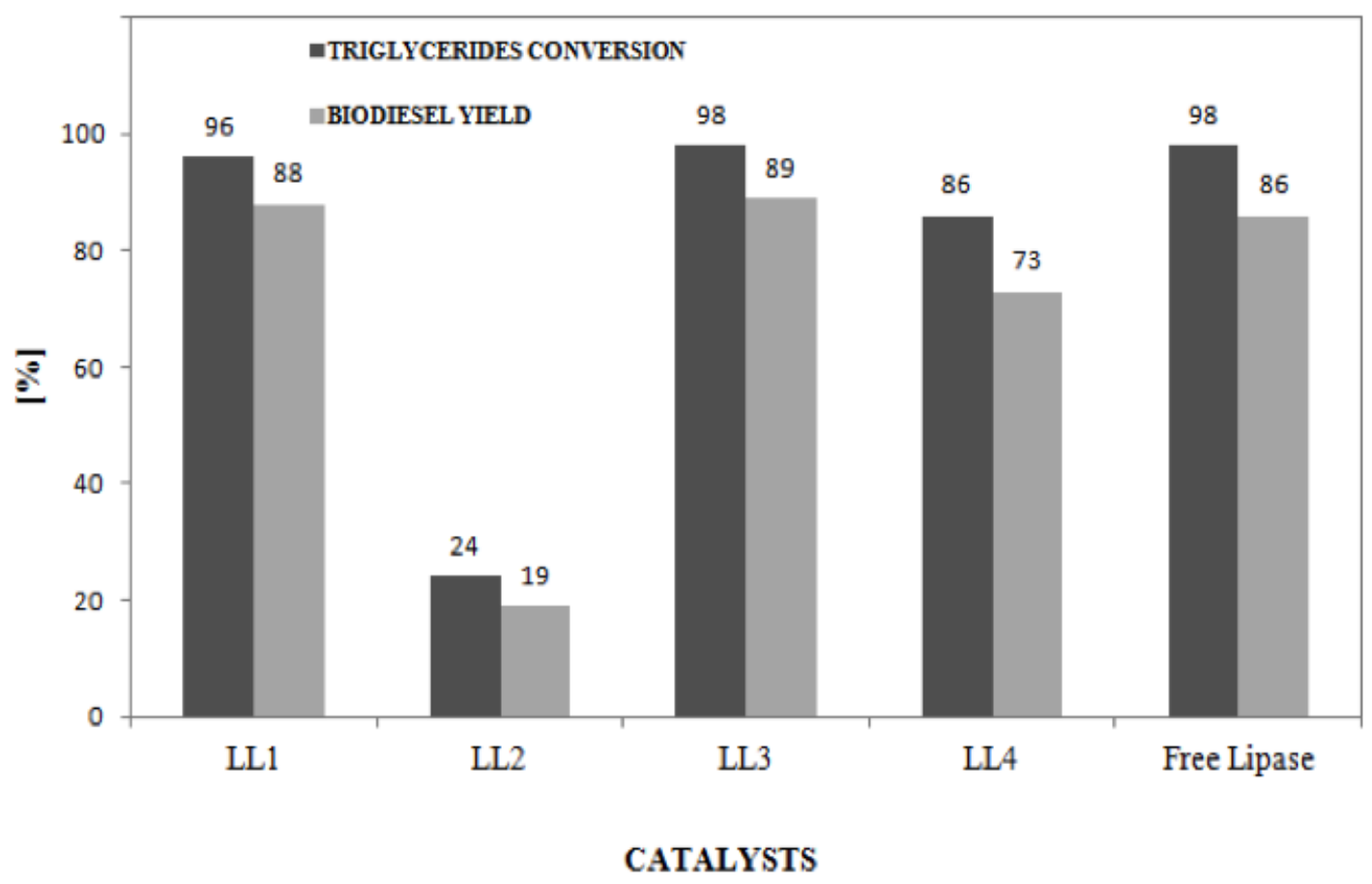

Figure 11

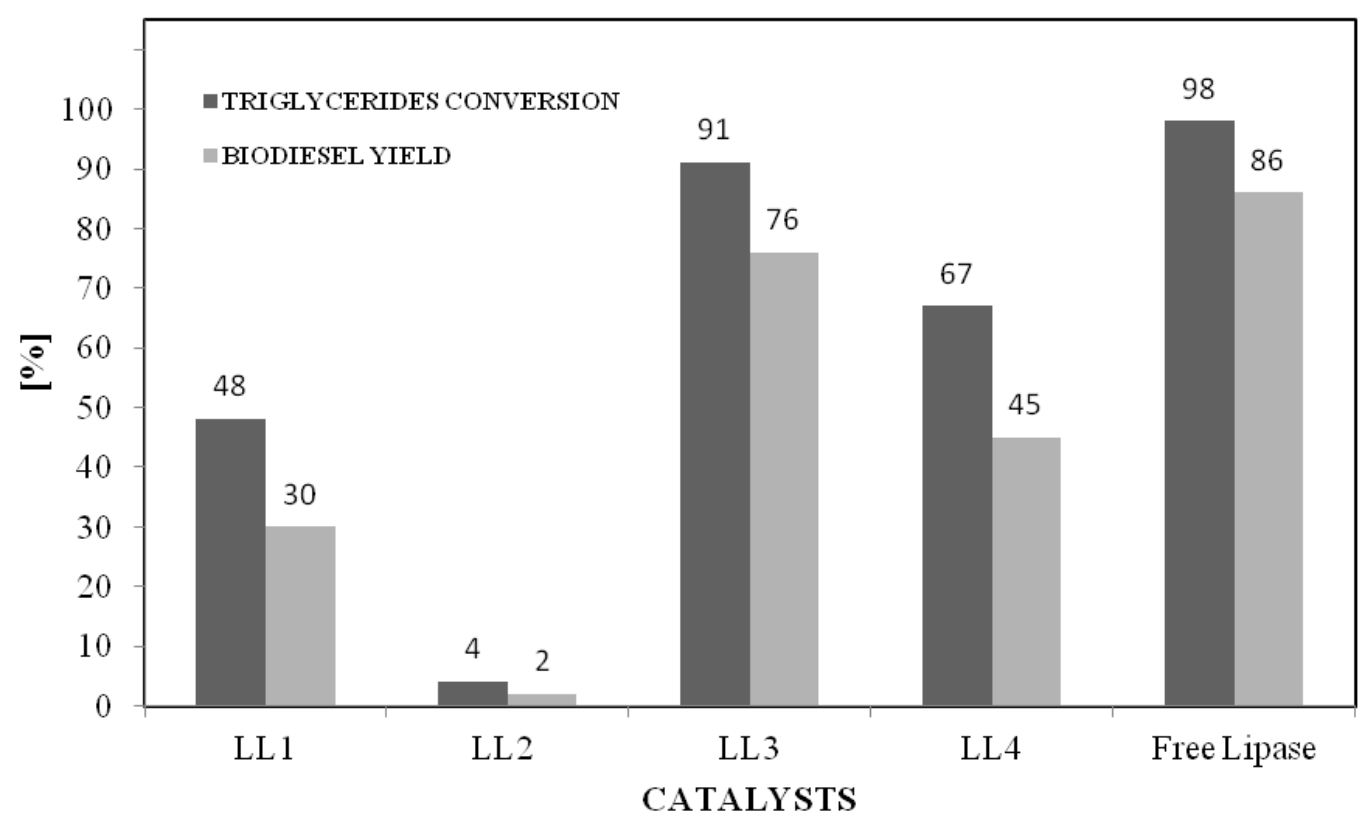

Figure 12 


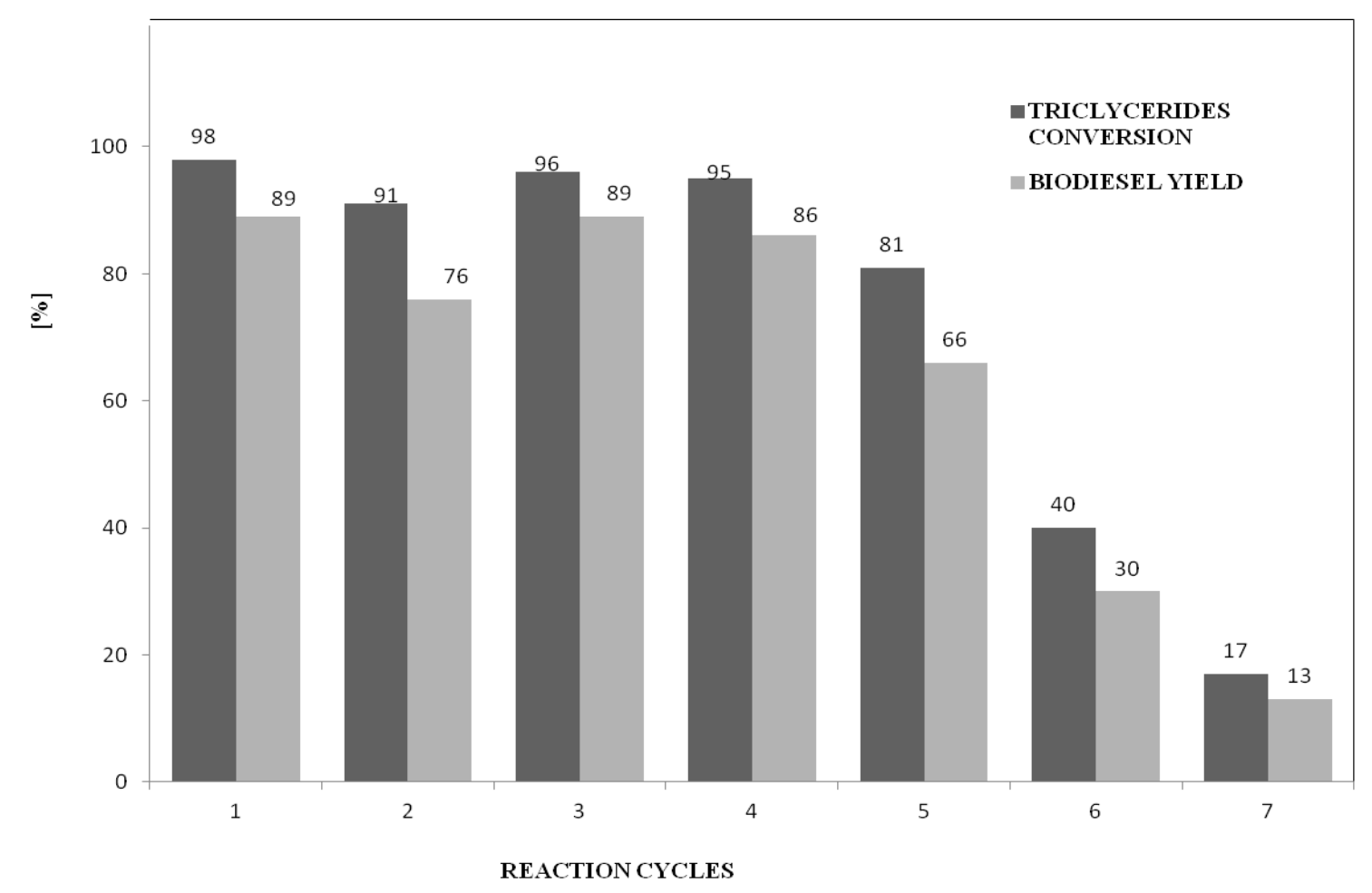

Figure 13

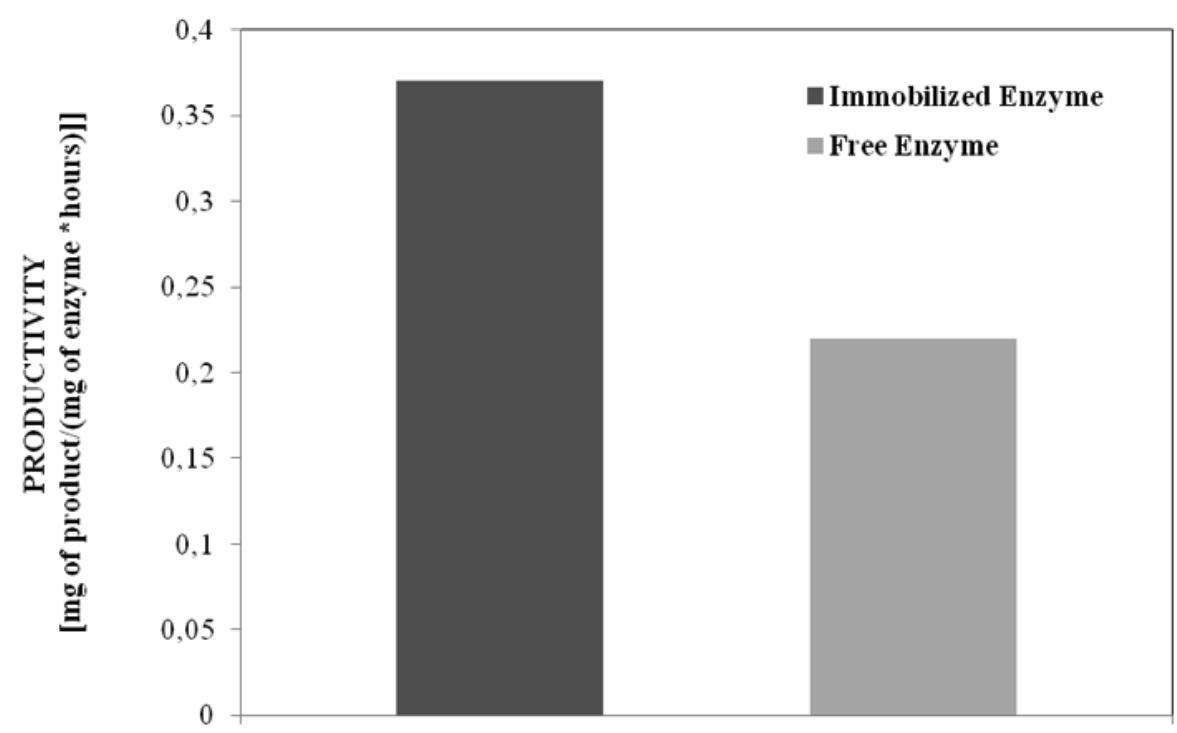

Figure 14 